\title{
Alarm based Solar Fencing and Pump Control System
}

\author{
S.Rajendran, A.Muthu Kumar, T.Hariprasath, V.Raj Abisekh, M.Karthik, S.Manoj,
}

\begin{abstract}
The protection of agriculture farm from the various wild lives is really a challenging task. To enhance the protection, the electric fences are provided with continues power supply. This existing system is modified by installing IR emitter and detector based virtual fence which is arranged in the circumference of the farm. The IR emitter virtual fence detects the interference of the wild animal and supplies power to the electric fence that provides a shock effect. Here in the proposed method, power consumption occurs only when there is a contact made when the animal strikes the fence.

Keywords : Solar Fencing, GSM, Micro controller, Pump control.
\end{abstract}

\section{INTRODUCTION}

Agriculture is the back bone of our country. Many farms are affected by the interventions of animals. Though they are adversely affected by their interruptions. In one model, we provide a limited electric shock to warn the unauthorized obstacles

. Their amounts of shock affect any lines. So, it is safable[1]. By the same time, we combined the moisture sensor with the entire setup. It's very hard to the farmers to operate the motor at the right time.

The Relay makes the pump to operate whenever the moisture level gets down below one set value. Once the water level or the moisture levels gets down below one set value then the pumps gets off [5]-[6].

Revised Manuscript Received on December 05, 2019.

S.Rajendran*, Department of electrical and electronic engineering, Kalasalingam Academy of Research and Education, Virudhunagar, India. rsrajendran2008@gmail.com

A.Muthu Kumar, Department of electronics and communication engineering, Kalsalingam Academy of research and education, Virudhunagar, India. muthuece.eng@gmail.com

T.Hariprasath, Department of electrical and electronic engineering, Kamaraj college of Engineering and Technology Virudhunagar, India, hariprasath1992@gmail.com

V.Raj Abisekh, Department of electrical and electronic engineering, Kalasalingam Academy of Research and Education, Virudhunagar, India. billaraj2496@gmail.com

M.Karthik, Department of electrical and electronic engineering, Kalasalingam Academy of Research and Education, Virudhunagar, India qkarthik94426@gmail.com

S.Manoj, Department of electrical and electronic engineering, Kalasalingam Academy of Research and Education, Virudhunagar, India. manojsaravanan91@gmail.com

\section{LITERATURE REVIEW}

Agriculture and Horticulture sector are rapid growth sector in our country. Many research areas are focused on increase the agriculture products with help of recent technologies [2]-[3]. If any living things crossed the fence the system will immediately sends the information to the concern owner through proper channel. But It is a very old model and the owner cannot come as fast as the trespassers enters the farm. Now many of them designed the system as to make alarm and send message to the owner of the land. They have connected with the GSM module [4]. Since the existing system just sends the message only it is outdated mechanism now.

\section{BLOCK DIAGRAM}

The proposed block diagram for solar fencing and pump control is given below.

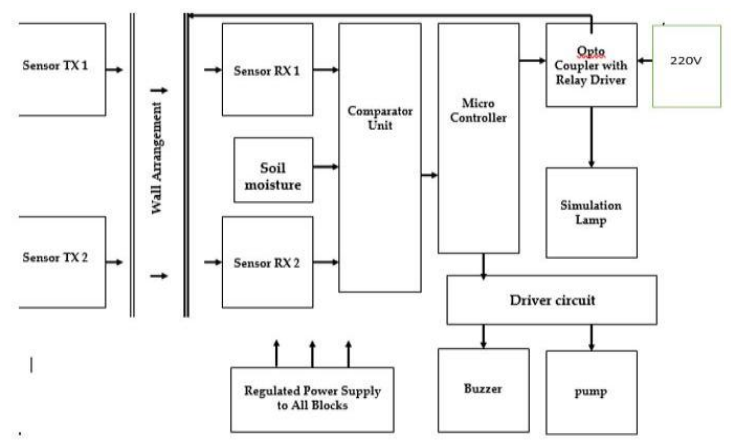

Fig.1.Block diagram for proposed work

The proposed set up is to mainly protect the farms from the animals and the humans. The overall system is cordially to make the farmers work very easier. The fence is planned to made for the four sides of the farm. We have planned to detect the entry with the LDR and the laser light. We have an idea of sending SMS through GSM to the concern owner in addition to make a sound with the buzzer. We are thinking to operate the pump with the solar in order to make the connections with the current. The moisture sensor will be used which is to be incorporated with the pump system. The entire system will be energized with a switch which is charged by a solar system or otherwise a battery. 


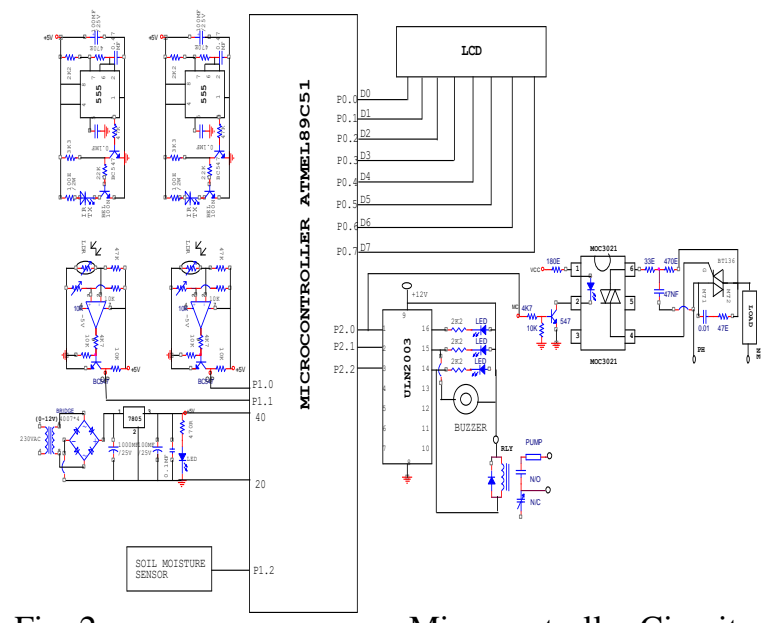

Fig. 2.

Microcontroller Circuit

The whole process is carried on using AT89C51 which provides the following standard features: $4 \mathrm{~K}$ bytes of flash, 128 bytes of RAM, 32 I/O lines, two 16 bit timer/ counters, a five vector two - level interrupt architecture, a full duplex serial port, on-chip oscillator and clock circuitry.

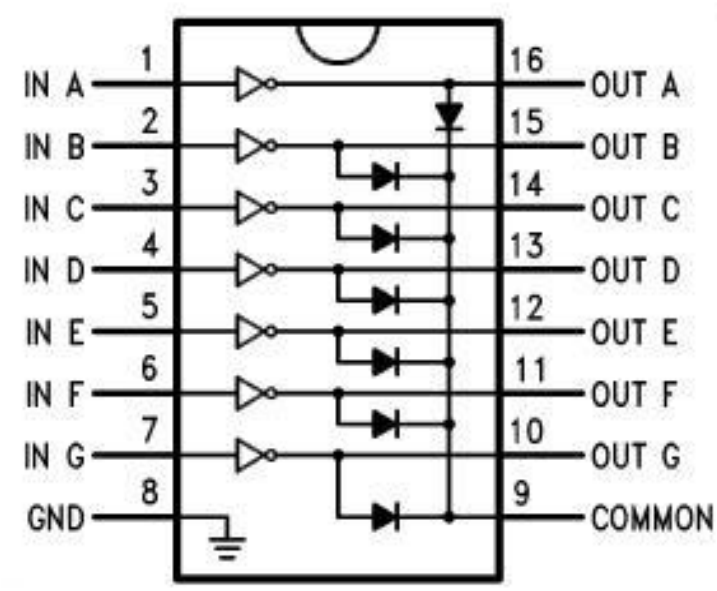

Fig.3.Pin Diagram

\section{RESULTS}

In the proposed system, IC 741 used for moisture sensor setup. It is a comparator IC. Since to operate the pump in ON\&OFF condition, we need a switching device, so we use a relay circuit. A laser is provided to pass the light to LDR. If there is any interruption in the laser light the normal one state output $(5 \mathrm{~V})$ becomes as zero state output. Then the zero state output goes to the controller. Where the program is dumped to activate the $230 \mathrm{~V}$ for the fence. LED is provided to show the indication that the $230 \mathrm{~V}$ supply is running through the fence shown in figure 4.

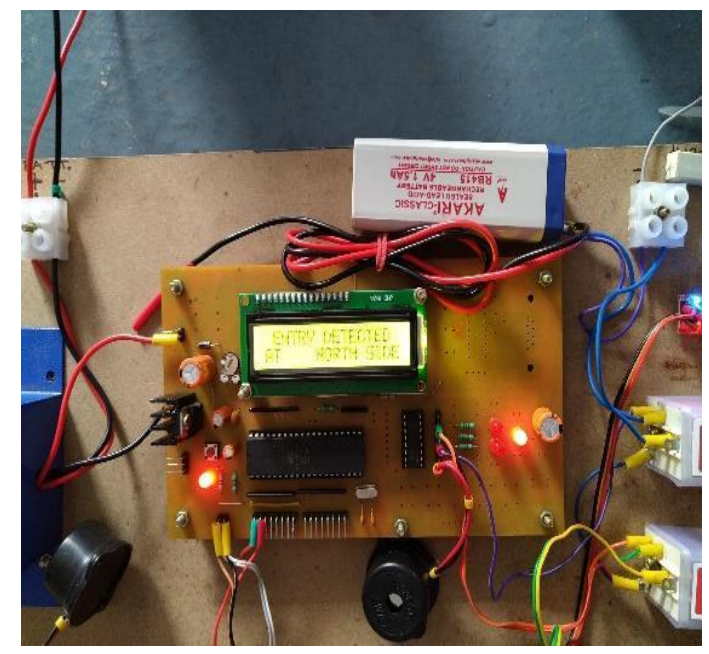

Fig. 4 Wild animal's entry display

At present we operate the setup with the $12 \mathrm{~V}$ battery. The Main switch is provided to switch in three positions, i.e. ON, OFF \& Charging through solar. The Output of the switch is given to the controller. A Filter is produced to provide pure DC. The Constant output is produced by the regulator which is kept at the main controller.

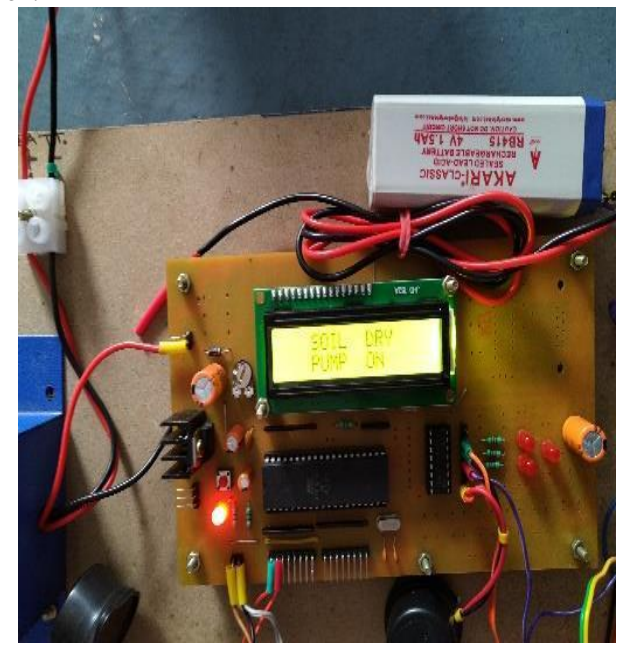

Fig. 5. Soil Moisture condition display

We have used the 780s regulator as we are using the $5 \mathrm{~V}$. The Indicator is provided to verify the system is ON condition. A 16*2 LCD in set up for show case the condition of the operation. AT mcl 8952IC the main IC consist of 40pins 20th pin is ground \&40th pin is supply. It has 4ports namely port 0 , port 1 , port2, port3. The ATmcl IC only accept the digital signal. The 0port is connected to LCD\& The first $\&$ third ports are the input $\&$ the second port is output. The LDR output is the input for one kit. Sensor output is also the input for one kit. The Output of one set up switching on the fever, if there is any interruption. A Buzzer is also activated when there is any interruption.

The above figure 5 shows that soil is dry and send a signal to turn on pump. The Crystal oscillator generates the required frequency of one's IC. ULN IC is used for the driver circuit. It is a 16 pin IC. Nineth pin supply and Eighth pin is ground. We can take up to 7 outputs from ULN IC but for one setup, we have taken just 3outputs. We have provides 3 LED for the indication of charging with the solar. 


\section{V.CONCLUSION}

The protection of agriculture farm is demanding situation as the cultivation of plantations and crops have been reducing year by year. The slopes of mountains where the movement of animals are higher, creates panic to the lands where cultivation is made. The proposed method of protection reduces the risk to the farmers and also impact of shock will not affect the animal life, so that the animals just don't enter the farmlands and also agriculture land is protected. The consumption of power is reduced to a greater extend and the saved power can be used for other farm purposes.

\section{REFERENCES}

1. Chunjuan Wei, Junjie Yang, Wu Zhu and Jian Lv, "A design of Alarm system for substation perimeter based on Laser Fence and Wireless Communication," IEEE conference on Computer Application and System Modeling (ICCASM), vol.3, pp.543-546, 2010.

2. D. M. Kadam, Atul R. Dange and V. P. Khambalkar, "Performance of solar power fencing system for agriculture," Journal of Agricultural Technology, vol.7, no.5, pp.11991209, ISSN 1686-91411, 2011

3. Gandhimathi, P. Madhumitha, T. Kalaivani, "Solar Power Fencing System for Agriculture Protection using GSM," An ISO 3297: 2007 Certified Organization), vol.4, no.12, December 2016.

4. G. Alex, Dr. M. Janakiranimathi, "Solar Based Plant Irrigation System," International Conference on Advances in Electrical, Electronics, Information, Communication and Bio-Informatics (AEEICB16), IEEE, 2016

5. Krishnamurthy B, M.Divya, S.Abhishek and Shashank, "Solar Fencing Unit and Alarm for Animal Entry Prevention" International Journal of Latest Engineering Research and Applications (IJLERA) ISSN: 2455-7137 Volume - 02, Issue - 05, May - 2017, PP - 128-135.

6. Suraj Dilip Chinchole, Sampada Milind Jadhav and Prof. R.K. Admane, "SOLAR BASED ELECTRONIC FENCING" International jounal of Electrical and Electronics Engineers, ISSN 2321-2055, Vol.9, issue no.1, January-June 2017.

\section{AUTHORS PROFILE}

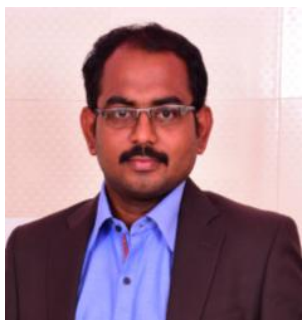

S.Rajendran received his UG degree in Electrical Engineering from Anna University, Chennai with First Class Distinction in 2009 and M.E. degree in Power Electronics and Drives from Anna University, Tiruchirappalli with First Class Distinction in 2011. Now He was pursuing $\mathrm{Ph} . \mathrm{D}$ in the field of reactive power compensation. Since July 2011, he has been working as an Assistant Professor in the Department of Electrical \& Electronics Engineering, Kalasalingam Academy of Research and Education, Krishnankoil, Virudhunagar District, Tamil Nadu and India. He has attended several international conferences and he has been actively involving himself in research since 2015. His current research interests include reactive power compensation in FACTS devices. He has actively participated in various faculty development programs, symposiums, orientation programs, workshops and national seminars. He has received Teaching Competency Award in the year 2017. He completed CLAD (Certified Lab view Associate Developer) in 2018.

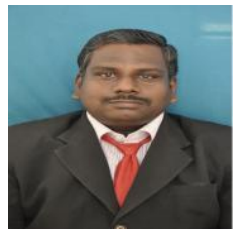

Dr. Muthukumar Arunachalam completed B.E. in Electronics and Communication Engineering from PSYEC, Madurai Kamaraj University with First Class Distinction in 2004. Following that, he completed M.E. in Applied Electronics from MSEC, Anna University and Ph.D. from Kalasalingamuniversity in 2006 and 2014 respectively. Currently, he is working as associate professor in Electronics and Communication Engineering department, Kalasalingam University, India, where he has been working since 2007 . He has more than 12 years of teaching experience in academic. His area of interest is Image processing, signal processing, biometrics and wireless communication. He is a life member of ISTE, IAENG. He has successfully guided $4 \mathrm{M}$.Tech and 33 batch B.Tech students. Currently he is guiding 5 Ph.D scholars. He has published 12 papers in International Journals and presented 43 papers in conferences. He is actively involved in the NBA
(National Board of Accreditation), NAAC (National Assessment and Accreditation Council), member of BoS (Board of Studies) and Academic Council of Kalasalingam University. He is recognized as Doctoral Committee member for 4 research scholars in Anna University, Chennai. He is the reviewer in international journals like, Biomedical Signal Processing \& Control (Elsevier Journal), Biometrics (IET Journal), The International Journal of Computer Aided Engineering and Technology (Inder science Journal), IEEE Transactions on Systems, Man and Cybernetics: Systems(IEEE Journal) and Bentham journal.

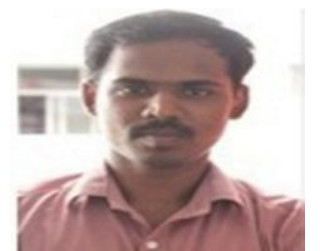

T.Hari Prasath received his UG degree in Electrical and Electronics Engineering in Mepco Schlenk Engineering College, Sivakasi with First Class Distinction in 2013 and M.E. degree in Industrial Safety Engineering from Mepco Schlenk Engineering College, Sivakasi, India, in 2015.. Now he was working as Assistan Professor in Kamaraj College of Engineering and Technology, Virudhunagar. He was published 6 papers in international journals and actively participated in various faculty development programs, symposiums, orientation programs, workshops and national seminars. Formerly, he was worked in Larson \& Toubro as Environment Health and Safety (EHS) Officer. He was honored with Best outgoing student in the year 2015 in Mepco Schlenk Engineering College, Sivakasi.

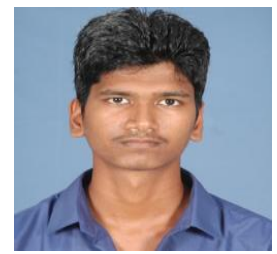

V.Raj Abisekh UG Student, persuinig B.Tech degree in the field of Electrical and Electronics Engineering, Kalasalingam Academy of Research and Education Anand Nagar, Krishnannkoil.Tamilnadu. He actively participated in various symposiums, workshop and other academic related activities. He was a student member in IE(I) India.

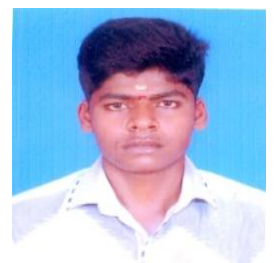

M.Karthik UG Student, persuinig B.Tech degree in the field of Electrical and Electronics Engineering, Kalasalingam Academy of Research and Education Anand Nagar, Krishnannkoil.Tamilnadu. He actively participated in various symposiums, workshop and other academic related activities. He was a student member in IE(I) India.

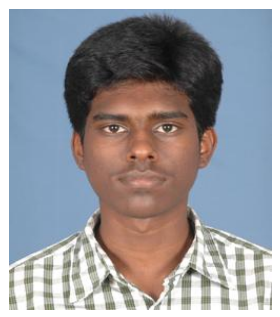

S.Manoj UG Student, persuinig B.Tech degree in the field of Electrical and Electronics Engineering, Kalasalingam Academy of Research and Education Anand Nagar, Krishnannkoil.Tamilnadu. He actively participated in various symposiums, workshop and other academic related activities. He was a student member in IE(I) India. He was an active member in Nature club activities. 